\title{
Recurrence Is Associated With Body Mass Index in Patients Undergoing a Single-Level Lumbar Disc Herniation Surgery
}

\author{
George Fotakopoulos ${ }^{\mathrm{a}, \mathrm{c}}$, Demosthenes Makris ${ }^{\mathrm{b}}$, Polikceni Kotlia ${ }^{\mathrm{b}}$, \\ Christos Tzerefos ${ }^{\mathrm{a}}$, Kostas Fountas ${ }^{\mathrm{a}}$
}

\begin{abstract}
Background: The aim of the study was to assess the body mass index (BMI) and other risk factors associated with lumbar disc herniation (LDH) and clinical outcomes, in patients who undergo surgery for single-level LDH.
\end{abstract}

Methods: This was a retrospective cohort study, affecting patients that underwent surgery for single-level LDH attending our hospital between July 2009 and January 2016. The mean follow-up period was 3.5 years ( $1-8$ years). To maintain adequately sized groups for analysis, level L2-L3 and L3-L4 herniations were grouped as upper disc levels (group A) and level L4-L5 (group B) and L5-S1 (group C) herniations were analyzed individually. Disk herniation was graded on T2-weighted sagittal magnetic resonance images by using a five-point scale. Pain assessment was made using the visual analog scale (VAS).

Results: Two hundred fifty-six (256) patients met study inclusion criteria. There were 138 males $(53.9 \%)$ with a mean age of $55.3 \pm 12.9$ years (range, 30 - 77). The association between A, B and C groups was analyzed, based on criteria such as age, sex, BMI, surgical techniques, diabetes, size of herniated disc, preoperative VAS, length of hospital stay, drop foot on admission, smoking, family history and history of injury to the lumbar spine, location of herniated disc (far lateral) and use of steroids. We found a statistically significant factor between groups in BMI $(\mathrm{P}=0.006)$, family history $(\mathrm{P}=0.001)$, location (far lateral) $(\mathrm{P}=0.003)$ and history of injury to the lumbar spine $(\mathrm{P}=0.003)$.

Conclusions: There may be an association between severity of disc degeneration and BMI (overweight and obese adults). Furthermore, spine and neurosurgeons should be aware that BMI might be related to patients' outcome.

Keywords: Lumbar disc herniation; Body mass index; Lumbar disc

Manuscript submitted February 20, 2018, accepted April 4, 2018

aDepartment of Neurosurgery, University Hospital of Thessaly, University Hospital of Larissa, Biopolis, 41110 Larissa, Thessaly, Greece

bepartment of Head of Critical Care, University of Thessaly, University Hospital of Larissa, Biopolis, 41110 Larissa, Thessaly, Greece

${ }^{c}$ Corresponding Author: George Fotakopoulos, Department of Neurosurgery, University Hospital of Thessaly, University Hospital of Larissa, Biopolis, 41110 Larissa, Thessaly, Greece. Email: gfotakop@yahoo.gr

doi: https://doi.org/10.14740/jocmr3121w degeneration

\section{Introduction}

The success of an effective surgical treatment in lumbar disc herniation (LDH) is of paramount importance for the surgeon and depends on various underlying factors. Surgical site infection, hemorrhage, nerve root injury, recurrence or residual disc, dural tear, discitis and epidural scar formation are only a few of these factors [1-4].

Especially in obese patients due to the coexistence with serious chronic disease related to morbidity and mortality but also the need of large incisions in order to have a better exposure [5].

Some studies have reported increased postoperative complications after spine surgery [6-8], while others have established a beneficial effect from surgery on obese patients with the appropriate indications $[9,10]$.

Recurrent LDH is a major cause of pain, disability and reoperation with the rate of recurrence after lumbar discectomy varying from $5 \%$ to $11 \%$ [11]. Despite the well-known effect of obesity on the musculoskeletal system, the establishment of obesity as a risk factor for recurrent lumbar disease remains controversial [6-8].

Previously published literature has investigated whether obesity increases the risk of recurrent LDH is unclear with conflicting data and indifferent about the association with different lumbar spine levels. Thus, the objective of this study was to investigate whether there is an association between BMI and recurrence in patients after surgical treatment of single-level LDH associated with different lumbar spine levels. This may help to a better management and surgical plan in those patients.

\section{Materials and Methods}

This retrospective cohort study was performed in the University Hospital of Larisa between July 2009 and January 2016. The mean follow-up was 3.5 years (from 1 to 8 years). This study was approved by the Institutional Review Board in accordance with current institutional regulations and a waiver for ICF since study was observational. 

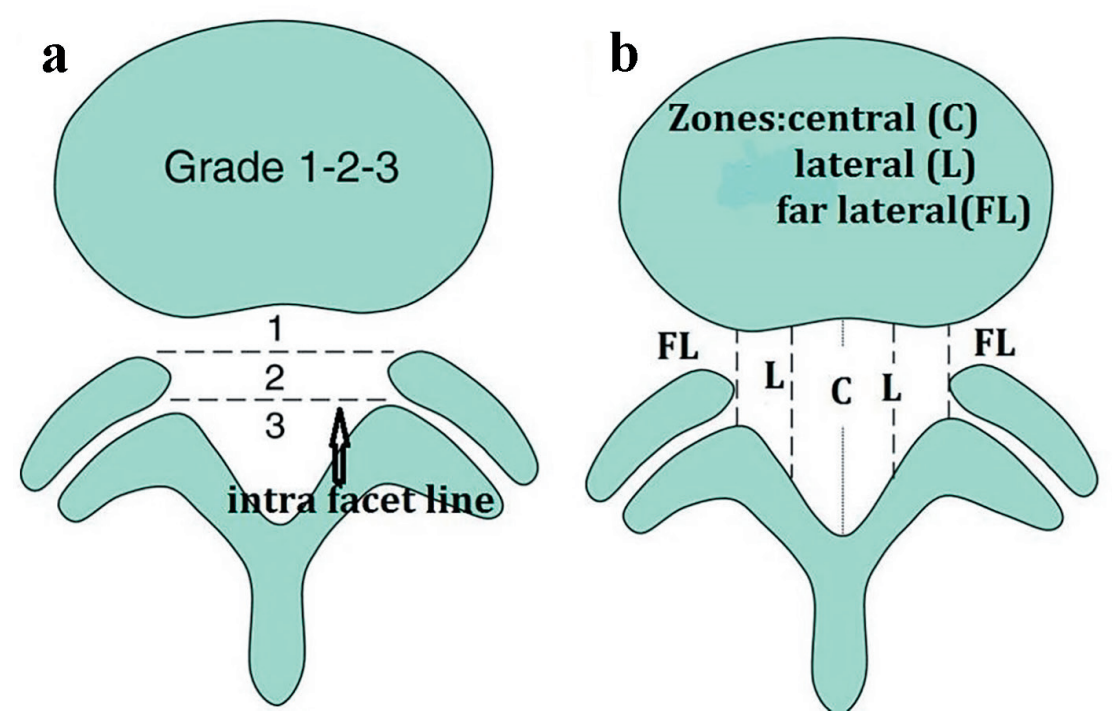

Figure 1. To portray the size of disc herniation, the lesion is described as 1,2 , or 3 (a). In reference to the intra-facet line, a determination is made as to whether the disc herniation extends up to or less than $50 \%$ of the distance from the non-herniated posterior aspect of the disc to the intra-facet line (size-1), or more than $50 \%$ of that distance (size-2). If the herniation extends altogether beyond the intra-facet line, it is termed a size-3 disc. To further qualify location of the disc herniation, the lesion is described as central, lateral or far lateral (b).

\section{Inclusion and exclusion criteria}

This study included patients that underwent surgery for singlelevel LDH. The exclusion criteria were: multilevel herniations, previous surgery of lumbar stenosis, history of injury to the lumbar spine with fracture and patients with skeletal deformities.

\section{Method of data retrieving}

Medication fill and medical encounter diagnoses data were extracted using data which encompass all inpatient and outpatient medical records from the database of our hospital.

All patients had imaging series that included an anterioposterior and lateral radiograph of the lumbar spine, immediately postoperatively and at 12 months postoperatively, to evaluate the range of motion and the device position. Using magnetic resonance imaging (MRI) to assess the size and location of disc herniation at the level of maximal extrusion in reference to a single intra-facet line drawn transversely across the lumbar canal, to and from the medial edges of the right and left facet joints.

\section{Patient groups}

Patients were divided into three groups (group A: with LDH in levels L2-L3 and L3-L4 (upper disc levels); group B: with LDH in level L4-L5; group C: with LDH at L5-S1 level).

\section{Outcomes}

Primary outcome was the recurrence of LDH. Recurrence was defined based on the following two criteria: 1) MRI confirmed two or three size disc herniation (Fig. 1a) and 2) when new signs and neurological symptoms occur after a period free of these (back pain and drop foot).

Secondary outcome was quality of life was scored using Odom's scale in immediate postoperative period and at the 12-month follow-up.

\section{Data definitions}

\section{MRI showing disc's size and location}

To illustrate the size of disc herniation, the lesion was described as 1, 2, or 3 (Fig. 1a). In reference to the intra-facet line, a determination was made as whether the disc herniation extends up to or less than $50 \%$ of the distance from the non-herniated posterior aspect of the disc to the intra-facet line (size-1), or more than $50 \%$ of that distance (size-2). If the herniation extends overall beyond the intra-facet line, it was termed a size-3 disc. In cases of more caudal or more cephalad maximal extrusions, this measurement was taken from the posterior edge of the vertebral cortex/endplate instead of the disc. To further qualify location of the disc herniation, the lesion is described as central, lateral or far lateral (Fig. 1b) [12].

\section{Quality of life assessment}

Quality of life was assessed by the Odom's scale, and the outcome was classified as: excellent (I) - improvement of preoperative symptoms and signs; good (II) - minimal persistence of preoperative symptoms, abnormal findings improved or un- 
Table 1. Baseline Characteristics of Patients

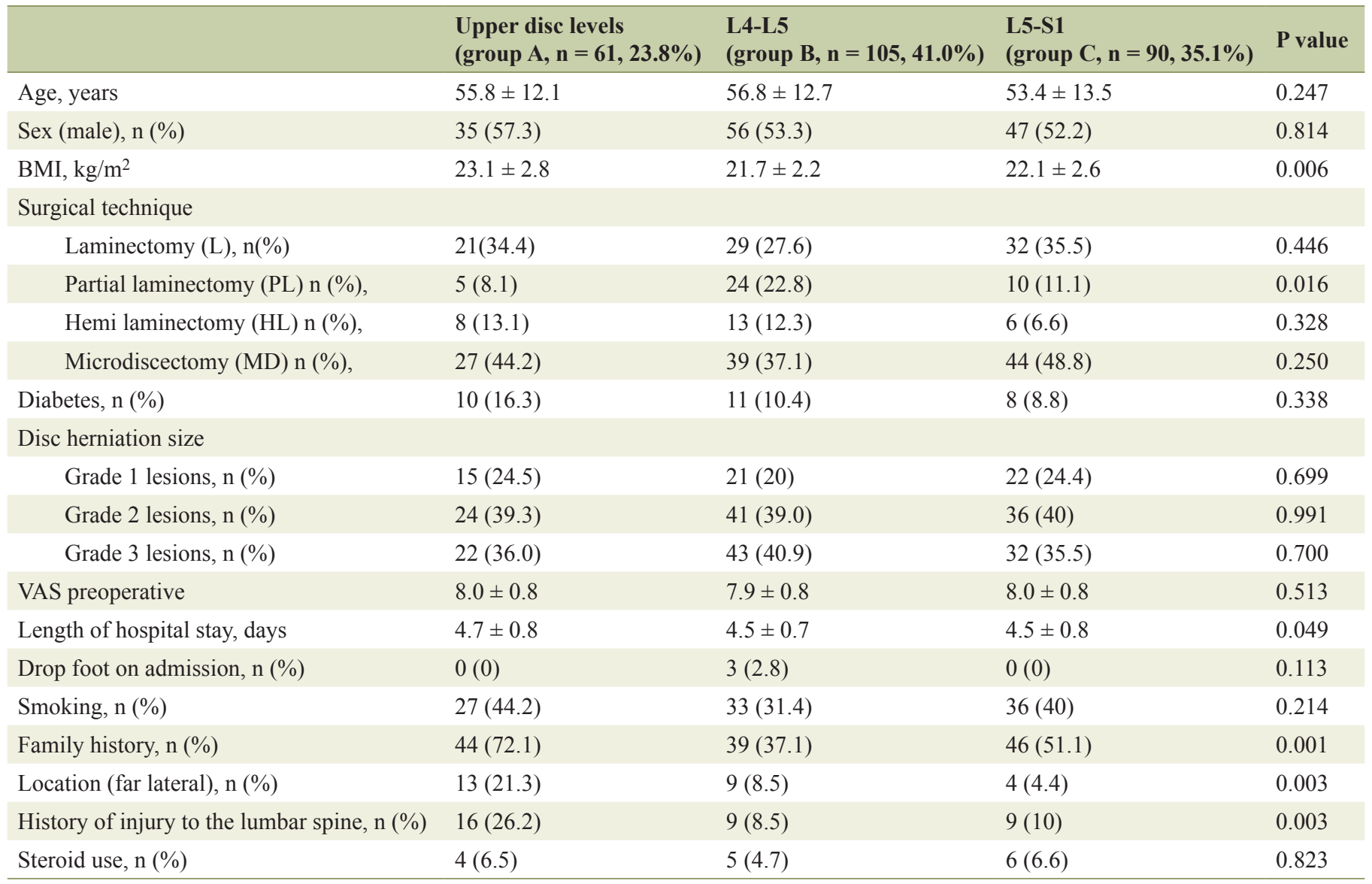

Data are presented as mean \pm SD, otherwise is indicated. BMI: body mass index; L: lumbar; S: sacral; VAS: visual analog scale.

changed; fair (III) - definite relief of some preoperative symptoms, other symptoms slightly improved or unchanged; poor (IV) - symptoms and signs unchanged or exacerbated [13].

BMI was derived from the mass (weight) and height of an individual. BMI was calculated as weight $(\mathrm{kg}) /$ height squared $\left(\mathrm{m}^{2}\right)$ [14]. Commonly accepted BMI ranges are underweight: under $18.5 \mathrm{~kg} / \mathrm{m}^{2}$, normal weight: 18.5 to $25 \mathrm{~kg} / \mathrm{m}^{2}$, overweight: 25 to $30 \mathrm{~kg} / \mathrm{m}^{2}$, obese: over $30 \mathrm{~kg} / \mathrm{m}^{2}$ [15].

\section{Indications for surgery as well as for the selection of each surgical technique}

MD: in patients who had herniated disk extended in one side only, fenestrations cause the minimal possible damage in spinal and thus offer more stability.

PL: in patients with very large (size-3) herniated disk, in order to keep a bridge of the bone and thus much more stability.

HL: in patients with far lateral herniated disc, in order to do foraminotomy to the adjacent and the outbound roots.

Standard (open) L: in patients with far lateral very large (size-3) herniated disc extended in two sides of the spinal, in order to do foraminotomy bilateral to the adjacent and the out- bound roots.

\section{Statistical analysis}

Data are expressed as mean $( \pm \mathrm{SD})$. Data were assessed for normality using the Shapiro-Wilkes test. Nominal data were analyzed using the Fisher's exact test. Continuous data were analyzed using the Student's $t$-test or the Mann-Whitney U-test as appropriate. Variables significantly associated with in univariate analysis were then entered in a multivariable analysis model. A P value $<0.05$ was considered as statistically significant. Statistical analyses were performed with the use of Statistical Product and Service Solutions (SPSS) software, version 15 (SPSS Inc., Chicago, IL, USA).

\section{Results}

Two hundred fifty-six (256) patients were included in this study. Baseline characteristics of study participants are shown in Table 1. Statistically significant differences were found between the group A and the rest of the patients in respect of BMI $(\mathrm{P}=0.001)$, length of hospital stay $(\mathrm{P}=0.049)$, family history $(\mathrm{P}=0.001)$, location (far lateral) $(\mathrm{P}=0.003)$ and history of 
Table 2. Outcomes of Patients

\begin{tabular}{|c|c|c|c|c|c|}
\hline & Total & Group A, n = $61(23.8 \%)$ & Group $B, n=105(41.0 \%)$ & Group C, $n=90(35.1 \%)$ & P value \\
\hline Recurrence, n (\%) & $19(7.4)$ & $11(18)$ & $4(3.8)$ & $4(4.4)$ & 0.001 \\
\hline \multicolumn{6}{|l|}{ Odom scale score } \\
\hline II & $14(5.4)$ & $3(4.9)$ & $7(6.6)$ & $4(4.4)$ & 0.775 \\
\hline III & $6(2.3)$ & $2(3.2)$ & $4(3.8)$ & $0(0)$ & 0.185 \\
\hline
\end{tabular}

Data are presented as $\mathrm{n}(\%)$, otherwise is indicated. L: lumbar; S: sacral.

injury to the lumbar spine $(\mathrm{P}=0.003)$ (Table 1$)$.

\section{Outcomes}

Clinical outcomes are shown in Table 2. Overall, recurrence rate was $7.4 \%$ (19/256 patients). Recurrence incidence was higher in group A compared to other groups $(\mathrm{P}=0.001)$ (Fig. 2 ). In addition the proportion of Odom score IV patients in group A was significantly greater compared to other groups.

Univariate analysis revealed that BMI and history of injury to the lumbar spine were associated with recurrence (Table 3 ). Multivariate analysis revealed that only BMI was an independent predictor for recurrence (OR $(95 \%$ CI) 1.53 (1.28 - 1.84)) (Table 4).

Receiver operating characteristic (ROC) analysis revealed that BMI presented the best performance to identify recurrence with an area under curve standard error (AUC (SE)) of 0.839 (0.060) $(\mathrm{P}=0.001)$, whereas a BMI value of $>24.4 \mathrm{~kg} / \mathrm{m}^{2}$ presented with $73.7 \%$ sensitivity and $90 \%$ specificity for recurrence (Table 5) (Fig. 3).

\section{Discussion}

Our findings suggest that in patients that underwent surgery for $\mathrm{LDH}$ with a $\mathrm{BMI}$ value $>24.4 \mathrm{~kg} / \mathrm{m}^{2}$, the recurrence rate

\section{BMI individual values among participants}

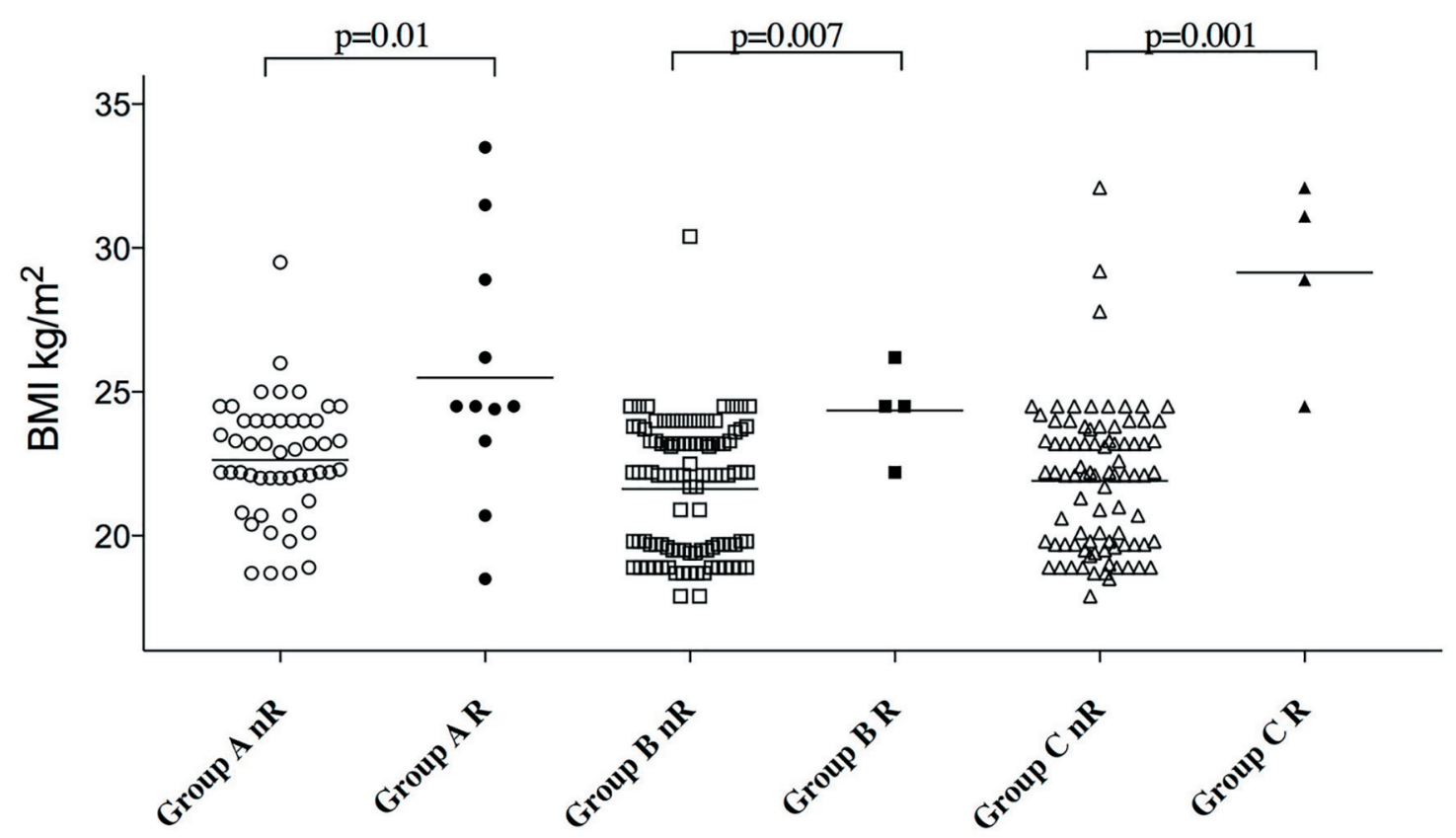

Figure 2. Body mass index (BMI) individual values among the three groups of participants according to the presence of recurrence or not. Bars represent mean values. Group A: 50 patients with no recurrence and 11 patients with recurrence; group B: 101 patients with no recurrence and four patients with recurrence; group C: 86 patients with no recurrence and four patients with recurrence. 
Table 3. Univariate Analysis for Recurrence

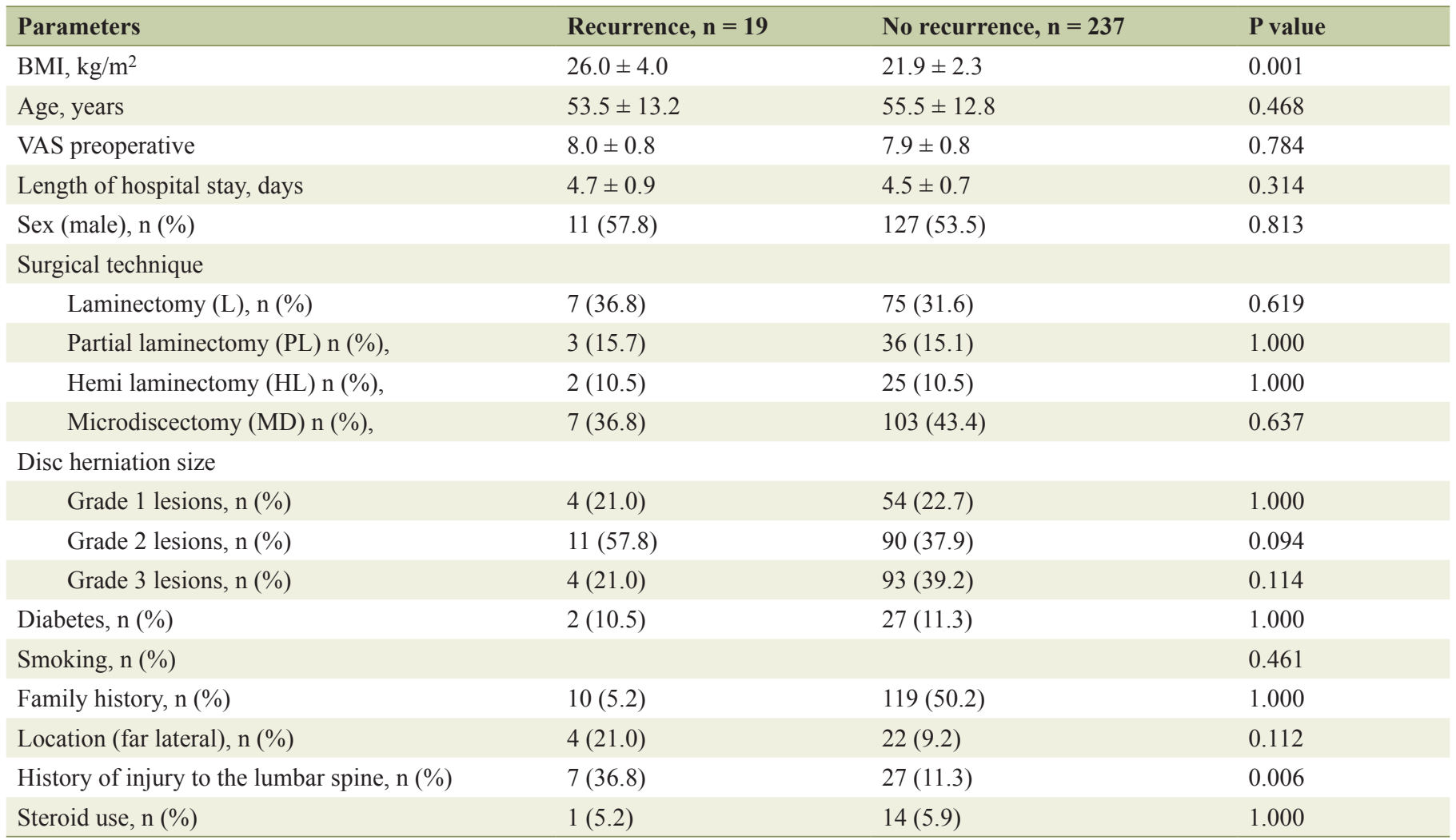

Data are presented as mean \pm SD, otherwise is indicated. BMI: body mass index; L: lumbar; S: sacral; VAS: visual analog scale.

was bigger and was independent. Furthermore, the incidence of recurrence in those patients was also increased when upper disc levels occur.

Although the optimal treatment for LDH has been object of great efforts to surgeons around the world, the effectiveness varies from $50 \%$ to $90 \%$ [16]. Thus, the LDH acquires the same importance, especially when it needs reoperation [17]. It is defined as recurrent back and/or leg pain after a definite pain-free period from initial surgery. The time after surgery that usually required returning the patients back to the operative room is between 3 and 50 days [17]. Interest is that lesions degenerated at the same level arising 4 - 6 weeks after surgery and tends to be traumatics [18]. In our data, this time estimated about 4 months. However, our knowledge about the mechanism and the causes following recurrence after LDH surgery was limited.

There are studies unable to identify any risk factor [19] and other who implicated the surgery technique and the location of the herniated disc (far lateral), as a possible reason [20].

Table 4. Multivariable Analysis (OR, $95 \% \mathrm{Cl})$

\begin{tabular}{llll}
\hline Name & OR & CI & P \\
\hline History of injury to the lumbar spine & 0.312 & $0.092-1.056$ & 0.061 \\
BMI & 1.536 & $1.280-1.842$ & 0.001 \\
\hline
\end{tabular}

BMI: body mass index; OR: odd ratio; $\mathrm{Cl}$ : confidence interval; $\mathrm{P}$ : value for the difference between groups; pVAS: postoperative visual analog scale; Inj: history of injury to the lumbar spine.
Although it is difficult to make comparisons with the literature different surgical techniques at surgery treatment of the $\mathrm{LDH}$, in order to eliminate this unpredictable parameter, we used four surgeries techniques (MD, L, HL and PL) that described above. In our study, the location (far lateral) of LDH was found statistically significant $(\mathrm{P}=0.003)$ between $\mathrm{A}, \mathrm{B}$ and $\mathrm{C}$ groups, but multivariate analysis was not independent factor for recurrence. Regarding surgical techniques, statistical difference in patients' outcomes was not revealed.

Many reports had classified the history of injury to the lumbar spine as main risk factor that led to recurrence of $\mathrm{LDH}$ $[3,17,21]$. Our study revealed a statistically significant difference between groups $\mathrm{A}$ and $\mathrm{B}$ and $\mathrm{A}$ and $\mathrm{C}(\mathrm{P}=0.003$ and $\mathrm{P}=0.013$, respectively). Instead, multivariate analysis (Table 4) illustrated that incidence at history of injury to the lumbar spine was not independent factor of recurrence $(\mathrm{P}=0.010)$. Thus, patients with injury in the past to the lumbar spine, when

Table 5. Statistical Findings for ROC

\begin{tabular}{llll} 
& Area & Std error & P value \\
\hline BMI-Rec & 0.839 & 0.060 & 0.001 \\
BMI-Odom I & 0.597 & 0.065 & 0.099 \\
BMI-Odom III & 0.537 & 0.127 & 0.759 \\
BMI-Odom IV & 0.386 & 0.141 & 0.302 \\
\hline
\end{tabular}

BMI: body mass index; Rec: recurrence. 


\section{BMI-Recurrence}

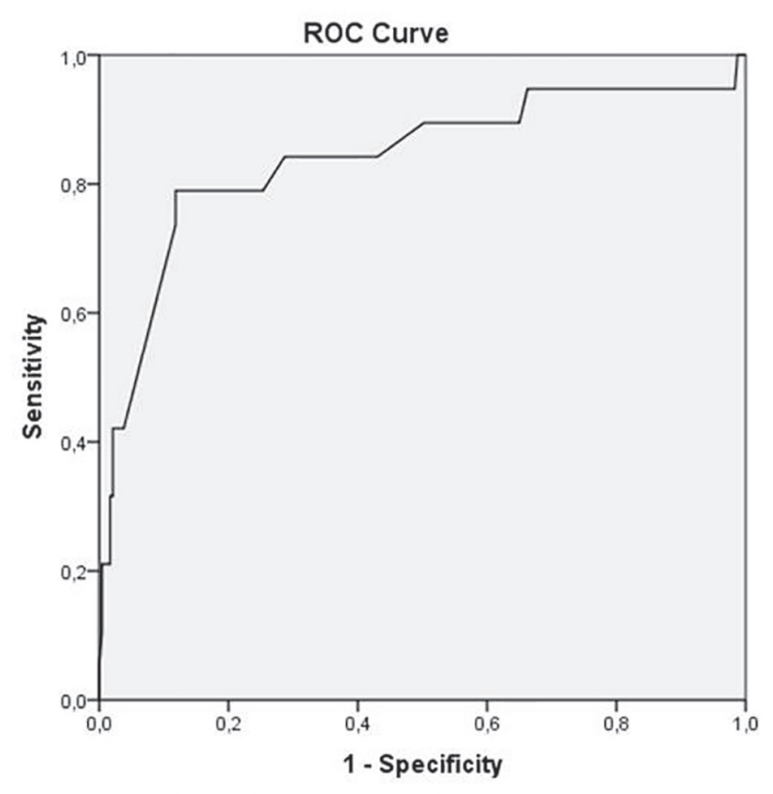

Diagonal segments are produced by ties.

Figure 3. Receiver operating characteristic $(R O C)$ curve, body mass index (BMI) - recurrence.

underwent surgery for LDH in upper lumbar disc levels had an increased incidence for recurrence only when associated with a BMI value $>24.4 \mathrm{~kg} / \mathrm{m}^{2}$.

However, the literature mentioned another possibly risk factor predisposing to recurrence LDH is diabetes, where patients suffer in much higher rate of LDH, possibly of a mechanism reducing the proteoglycans density at the disc [22]. Another study reports that in elderly patients the LDH recurrence was limited and that had satisfactory outcome [23]. Indeed our study did not find any statistically significant difference between groups compared with the age and diabetes.

On the other hand, the disc herniated volume as depicted at the magnetic resonance imaging (MRI) correlates with the rate of the LDH recurrence [24]. However, in our study, there was not any correlation between grade of LDH and recurrence.

It has been reported also that obese patients appear to have a relatively lower risk for LDH recurrence [17]. On the other hand, based on the retrospective nature of our study, we found a statistically significant association between BMI, LDH and clinical outcome, in patients who undergo surgery for singlelevel LDH. In our study also, ROC analysis showed that BMI and recurrence presented the best performance $(\mathrm{P}=0.001)$; a BMI value of $>24.4 \mathrm{~kg} / \mathrm{m}^{2}$ presented with $73.7 \%$ sensitivity and $90 \%$ specificity. The recurrence rate in upper disc levels (group A) was statistically significant compared with the other groups $(\mathrm{P}=0.001)$. Thus in patients that underwent surgery for LDH with a BMI value $>24.4 \mathrm{~kg} / \mathrm{m}^{2}$, the recurrence rate was bigger when upper disc levels occur.

Regardless of herniation level, some studies report that the relative advantage for surgery is greater for patients with herniation at higher lumbar levels, with non-operative treatment being less effective in these patients compared with those at L4-L5 and L5-S1 [25]. In our data, the incidence of recurrence after surgery for disc herniation in group A was 11 cases (18\%) compared with group B (3.8\%) and group C (4.4\%) with a statistically significant difference between groups $\mathrm{A}$ and $\mathrm{B}$ and $\mathrm{A}$ and $\mathrm{C}(\mathrm{P}=0.003$ and $\mathrm{P}=0.013$, respectively). This means that the recurrence rate after surgery for LDH was bigger when upper disc levels occurred.

On the other hand, the medical literature is mixed on whether people who smoke are at greater risk for a new herniation following a discectomy [26-28]. Our study suggests that there was not any correlation in groups between smoke and patients' outcomes.

One extensive study also found that a family history of lumbar herniated discs is the best predictor of a future herniation [14]. Our data showed a statistically significant difference between groups $\mathrm{A}$ and $\mathrm{B}$ and $\mathrm{A}$ and $\mathrm{C}$ (with $\mathrm{P}=0.003$ and $\mathrm{P}=$ 0.013 , respectively), but in multivariate analysis there was not an independent factor for recurrence.

There are several points of our study that have to be considered when interpreting its results. Firstly, data were retrospectively collected and in this respect most sources of error due to confounding and bias are more common compared to a randomized study. In this respect, definitive conclusion is hard to be drawn. Another point that should be clarified is the relationship between recurrence assessed and different characteristics of each surgical technique. In order to clarify this point we introduced in analyses variables that describe different clinical parameters, i.e. family history, location, and treatment modalities (length of therapy, steroid use). In addition, it should be pointed out that this is a one-center study and the population studied was small.

\section{Conclusion}

We believe that an association between the severity of disc degeneration and weight in overweight and obese adults exists and surgeons should be aware that BMI might be related to patients' outcome, mainly to those with a BMI value $>25.4 \mathrm{~kg} /$ $\mathrm{m}^{2}$. Furthermore, the incidence of recurrence in those patients was also increased when operated on LDH in upper disc levels compared with those patients that underwent surgery for disc herniation in L4-L5 and L5-S1 levels. May be more studies are needed in order to understand why these patients are more prone to the appearance of the LDH.

\section{Conflict of Interest}

Authors declare that they do not have any conflict of interest in regards to this performed study.

\section{Funding}

None. 


\section{References}

1. Kelsey JL, Githens PB, O'Conner T, Weil U, Calogero JA, Holford TR, White AA, 3rd, et al. Acute prolapsed lumbar intervertebral disc. An epidemiologic study with special reference to driving automobiles and cigarette smoking. Spine (Phila Pa 1976). 1984;9(6):608-613.

2. Mysliwiec LW, Cholewicki J, Winkelpleck MD, Eis GP. MSU classification for herniated lumbar discs on MRI: toward developing objective criteria for surgical selection. Eur Spine J. 2010;19(7):1087-1093.

3. Suk KS, Lee HM, Moon SH, Kim NH. Recurrent lumbar disc herniation: results of operative management. Spine (Phila Pa 1976). 2001;26(6):672-676.

4. Swartz KR, Trost GR. Recurrent lumbar disc herniation. Neurosurg Focus. 2003;15(3):E10.

5. Department of Health (2013) Reducing Obesity and Improving Diet. https://www.gov.uk/government/policies/ reducing-obesity-and-improving-diet.pdf Accessed 31 May 2017.

6. Andreshak TG, An HS, Hall J, Stein B. Lumbar spine surgery in the obese patient. J Spinal Disord. 1997;10(5):376379.

7. Patel N, Bagan B, Vadera S, Maltenfort MG, Deutsch H, Vaccaro AR, Harrop J, et al. Obesity and spine surgery: relation to perioperative complications. J Neurosurg Spine. 2007;6(4):291-297.

8. Pull ter Gunne AF, Cohen DB. Incidence, prevalence, and analysis of risk factors for surgical site infection following adult spinal surgery. Spine (Phila Pa 1976). 2009;34(13):1422-1428.

9. Gepstein R, Shabat S, Arinzon ZH, Berner Y, Catz A, Folman Y. Does obesity affect the results of lumbar decompressive spinal surgery in the elderly? Clin Orthop Relat Res. 2004;426:138-144.

10. Kardaun JW, White LR, Shaffer WO. Acute complications in patients with surgical treatment of lumbar herniated disc. J Spinal Disord. 1990;3(1):30-38.

11. McCulloch JA. Focus issue on lumbar disc herniation: macro- and microdiscectomy. Spine (Phila Pa 1976). 1996;21(24 Suppl):45S-56S.

12. Mundt DJ, Kelsey JL, Golden AL, Pastides H, Berg AT, Sklar J, Hosea T, et al. An epidemiologic study of non-occupational lifting as a risk factor for herniated lumbar intervertebral disc. The Northeast Collaborative Group on Low Back Pain. Spine (Phila Pa 1976). 1993;18(5):595602.

13. Odom GL, Finney W, Woodhall B. Cervical disk lesions. J Am Med Assoc. 1958;166(1):23-28.

14. Battie MC, Videman T, Kaprio J, Gibbons LE, Gill K, Manninen H, Saarela J, et al. The Twin Spine Study: contributions to a changing view of disc degeneration.
Spine J. 2009;9(1):47-59.

15. Consultation WHOE. Appropriate body-mass index for Asian populations and its implications for policy and intervention strategies. Lancet. 2004;363(9403):157-163.

16. Veresciagina K, Spakauskas B, Ambrozaitis KV. Clinical outcomes of patients with lumbar disc herniation, selected for one-level open-discectomy and microdiscectomy. Eur Spine J. 2010;19(9):1450-1458.

17. Moliterno JA, Knopman J, Parikh K, Cohan JN, Huang $\mathrm{QD}$, Aaker GD, Grivoyannis AD, et al. Results and risk factors for recurrence following single-level tubular lumbar microdiscectomy. J Neurosurg Spine. 2010;12(6):680686.

18. Williams RW. Microlumbar discectomy: a conservative surgical approach to the virgin herniated lumbar disc. Spine (Phila Pa 1976). 1978;3(2):175-182.

19. Palmer S. Use of a tubular retractor system in microscopic lumbar discectomy: 1 year prospective results in 135 patients. Neurosurg Focus. 2002;13(2):E5.

20. Kogias E, Vougioukas VI, Hubbe U, Halatsch ME. Minimally invasive approach for the treatment of lateral lumbar disc herniations. Technique and results. Minim Invasive Neurosurg. 2007;50(3):160-162.

21. Cinotti G, Gumina S, Giannicola G, Postacchini F. Contralateral recurrent lumbar disc herniation. Results of discectomy compared with those in primary herniation. Spine (Phila Pa 1976). 1999;24(8):800-806.

22. Mobbs RJ, Newcombe RL, Chandran KN. Lumbar discectomy and the diabetic patient: incidence and outcome. J Clin Neurosci. 2001;8(1):10-13.

23. Warnecke K, Friedrich H. [Results of intervertebral disk surgery in advanced age]. Neurochirurgia (Stuttg). 1990;33(2):45-49.

24. Dora C, Schmid MR, Elfering A, Zanetti M, Hodler J, Boos N. Lumbar disk herniation: do MR imaging findings predict recurrence after surgical diskectomy? Radiology. 2005;235(2):562-567.

25. Lurie JD, Faucett SC, Hanscom B, Tosteson TD, Ball PA, Abdu WA, Frymoyer JW, et al. Lumbar discectomy outcomes vary by herniation level in the Spine Patient Outcomes Research Trial. J Bone Joint Surg Am. 2008;90(9):1811-1819.

26. Huang W, Qian Y, Zheng K, Yu L, Yu X. Is smoking a risk factor for lumbar disc herniation? Eur Spine J. 2016;25(1):168-176.

27. Leven D, Passias PG, Errico TJ, Lafage V, Bianco K, Lee A, Lurie JD, et al. Risk factors for reoperation in patients treated surgically for intervertebral disc herniation: a subanalysis of eight-year SPORT data. J Bone Joint Surg Am. 2015;97(16):1316-1325.

28. Shin BJ. Risk factors for recurrent lumbar disc herniations. Asian Spine J. 2014;8(2):211-215. 